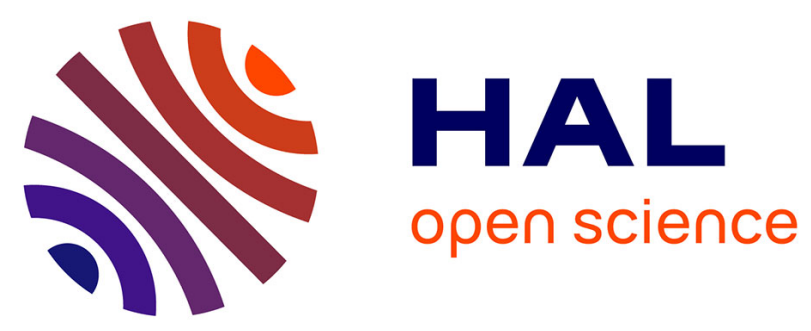

\title{
How the experimental knowledge of the irreversible fouling distribution can contribute to understand the fluid circulation in a spiral ultrafiltration membrane.
} Murielle Rabiller-Baudry, Ndeye Wemsy Diagne, Dorian Lebordais

\section{- To cite this version:}

Murielle Rabiller-Baudry, Ndeye Wemsy Diagne, Dorian Lebordais. How the experimental knowledge of the irreversible fouling distribution can contribute to understand the fluid circulation in a spiral ultrafiltration membrane.. Separation and Purification Technology, 2014, 136, pp.157-167. 10.1016/j.seppur.2014.08.040 . hal-01069494

\author{
HAL Id: hal-01069494 \\ https://hal.science/hal-01069494
}

Submitted on 8 Oct 2014

HAL is a multi-disciplinary open access archive for the deposit and dissemination of scientific research documents, whether they are published or not. The documents may come from teaching and research institutions in France or abroad, or from public or private research centers.
L'archive ouverte pluridisciplinaire $\mathbf{H A L}$, est destinée au dépôt et à la diffusion de documents scientifiques de niveau recherche, publiés ou non, émanant des établissements d'enseignement et de recherche français ou étrangers, des laboratoires publics ou privés. 
Submitted to Separation and Purification Technology - January 31 st 2014

Revised version submitted August 26 th

\title{
How the experimental knowledge of the irreversible fouling distribution can contribute to understand the fluid circulation in a spiral ultrafiltration membrane
}

Murielle RABILLER-BAUDRY *, Ndéye Wemsy DIAGNE, Dorian LEBORDAIS

Université de Rennes 1, «Institut des Sciences Chimiques de Rennes » UMR-CNRS 6226, 263 avenue du Général Leclerc, CS 74205, case 1011, 35042 Rennes cedex, France

corresponding author : murielle.rabiller-baudry@univ-rennes1.fr

\section{KEYWORDS:}

Ultrafiltration, spiral membrane, flat membrane, hydrodynamic, critical flux, limiting flux, fouling, proteins, membrane autopsy.

\begin{abstract}
It is commonly thought that in a spiral membrane the fouling is high at the module inlet and progressively decreases toward the outlet. Thanks to an experimental mapping of the irreversible fouling existing in a spiral membrane of $6.5 \mathrm{~m}^{2}$ area, this paper shows that it is not systematically true and that the fouling distribution can be much more complex.

This paper shows also in what extent the mapping of the irreversible fouling existing in a spiral membrane is a powerful approach to deal with the role of the velocity/turbulences gradient that can be experimentally studied independently of the transmembrane pressure gradient in appropriate filtering conditions.

The fouling distribution suggests that the velocity/turbulences are roughly constant on $50 \%$ of the membrane area located in its center when dealing with a radial dimension, whereas part of this mean position, velocity/turbulences can increase or decrease.
\end{abstract}

\section{INTRODUCTION}

Fouling systematically occurs during ultrafiltration (UF) of skim milk as for all dairy fluids filtered by polyethersulfone (PES) based membranes. Part of this fouling is irreversible (not removed by a simple water rinsing) and is known to be only made of proteins in the particular 
case of skim milk UF $[\mathbf{1}, \mathbf{2}]$. This irreversible part represents the target of the cleaning operation that is a well-known bottleneck of membrane processes in food industry. The physico-chemical interactions between the filtered fluid and the membrane material have a crucial role on the membrane fouling [3], but the membrane geometry, impacting the overall hydrodynamic, is also an important criterion. Spiral membrane is a quite complicated geometry in which the fluid circulation, responsible of part of the fouling deposit origin, is still not well understood.

In literature several approaches are reported when studying fouling distribution in close correlation with hydrodynamics. One type of approach deals with simulations at local scale, mainly using computational fluid dynamics (CFD) to investigate flow patterns [4-7] and foulant deposition [8] around feed spacers. For instance, experimental and numerical (CFD) results, obtained for twelve different flow-aligned spacer structures under different hydrodynamic conditions are investigated in order to gain insight into the flow and mass transfer profiles inside the channels of membrane modules: mass transfer results demonstrated that the modified friction factor could be used for selecting the best spacer in terms of mass transfer efficiency [4]. Rahimi et al. [5] report CFD and experimental studies on microfiltration fouling of a blue indigo solution. A hydrophilized PVDF membrane is used and experiments are carried out at cross-flow velocities ranging from 0.5 to $1.3 \mathrm{~m} . \mathrm{s}^{-1}$. The fouled membranes are analysed using Scanning Electron Microscope (SEM) pictures. The predicted shear stress distributions upon the membrane, determined from a 3-D CFD modelling carried out using FLUENT 6.2 code, are used to explain the observed fouling. CFD simulations of particle deposition in a spiral-wound membrane module show that there are inherent changes in the deposition profile in the spacer-filled channel due to variations in curvature on particle transport [8]. According to the authors, a microscopic understanding derived from the CFD analysis could improve module design and enhance membrane module performance. All these studies suffer more or less from a lack of experimental validation at a scale compatible with a whole spiral element.

Nevertheless, some recent studies attempt to overcome this conclusion coupling CFD calculations and in-situ analysis of fouling distribution in spiral membrane [9-14]. Graf von der Schulenburg et al. [9] and Creber et al. [10-12] studied the membrane fouling directly in spiral wounded membranes using nuclear magnetic resonance (NMR) for magnetic resonance imaging (MRI). This non-invasive technique enables quite thick biofilm to be identified (few microns) directly in a whole RO spiral element used for water treatment. The effective 
membrane surface area is quantified from images and conclusions drawn from the reduction of the feed channel observed by MRI are in reasonable agreement with simulations proposed by the authors. Vrouwenvelder et al. [14] explain that in spiral wound membrane modules, two types of pressure drop can be discriminated: the trans-membrane pressure drop (TMP) and the feed spacer channel pressure drop (FCP), also named longitudinal pressure drop. They suggest that in extensively pre-treated water of NF and RO, biofouling (mainly corresponding to biofilm of micro-organisms) is a feed channel pressure drop problem. Moreover, in a another paper [13] they propose a 3D mathematical model showing the same trends for (i) feed channel pressure drop, (ii) biomass accumulation, (iii) velocity distribution profile resulting in regions of low and high liquid flow velocity.

So it appears from literature that among the possible origins of variation in fouling deposit in the spiral membrane and at least in the efficiency of the subsequent step of cleaning, is the important pressure drop existing along the spiral element and leading to a transmembrane pressure (TMP) gradient. Moreover, if an average cross- flow velocity can be estimated from the retentate flow rate and the thickness of the liquid channel, assumed to be that of the retentate spacers inserted between two membrane sheets, the local velocity distribution due to the occurrence of retentate spacers is far from being well understood. Of course, it is quite well known that the insertion of spacers in the liquid channel is a real need to promote provoke turbulences and to lower the overall fouling $[1,2,4-7]$.

In the particular case of fouling by dairy fluids, membrane irreversible fouling is assumed to depend on both the transmembrane pressure (TMP) used and on the cross-flow velocity $(v)$ of the feed fluid, and also probably on a combination of these two parameters. For instance, at a given average apparent constant velocity (corresponding to the velocity calculated in the free channel) we have shown in a previous study that the irreversible fouling (target of the cleaning) obtained by UF of skim milk with a PES membrane at critical TMP is half that obtained at higher TMP (including TMP slightly higher than the limiting one) [15].

- Remember that the concept of critical flux, firstly introduced by Field et al. [16] in 1995 and modified by the same main author in 2011 [17], proposes a theoretical base for the fouling mastering during filtration by the minimization of its irreversible part according to the adequate choice of the TMP and its corresponding permeate flux $(J)$ that must be lower than a critical value $\left(J_{\text {critical }}\right)$. The critical flux concept was initially developed for a steady state 
system with a well-mixed feed compartment such as stirred cell and, of course, spiral membranes don't achieve this condition and consequently, significant variations are expected in both radial and axial dimensions. Nevertheless, even if this concept is, at first sight, of limited applicability to spiral elements because of great deviation from ideal conditions, it has been previously shown that it can be used [3] and applied in a close form, more recently called "threshold flux concept" [17] which does not rely on the establishment of steady state conditions with a homogeneous concentration in the feed -

Diagne et al. [15] have observed the threshold type of the critical flux in the case of skim milk $\mathrm{UF}$ at $50^{\circ} \mathrm{C}$ with a $5-10 \mathrm{~kg} \cdot \mathrm{mol}^{-1} \mathrm{PES}$ membrane. At an average estimated cross-flow velocity close to $0.3 \mathrm{~m} . \mathrm{s}^{-1}$ either in spiral and flat configuration (both in presence of turbulences that were not quantified but due to similar $1 \mathrm{~mm}$ thickness spacers inserted in the feed liquid channel), the critical TMP was observed to be 1.5 bar, whereas the limiting one was shown to be 3.5 bar. This means that:

- for $J<J_{\text {critical }}$, the flux lowering (when compared to the water flux) is due to the superimposition of the concentration polarisation (fully reversible) and of irreversible fouling due to adsorption (in the same amount as without any applied pressure).

- for $J>J_{\text {critical }}$ the irreversible part of the fouling severely increases.

Nevertheless, at this average cross-flow velocity estimated to be $0.34-0.37 \mathrm{~m} . \mathrm{s}^{-1}$, using a 4333 spiral membrane (4.3" diameter and 33" length), when the membrane works at an average TMP of 2.6 bar, the TMP along the membrane varies in the 3.7- 1.5 bar range because of the 2.2 bar pressure drop along the spiral element. Consequently, in this particular case, the main part of the membrane filters at flux higher than the limiting flux (associated to the limiting $\mathrm{TMP}, \mathrm{TMP}_{\text {limiting }}=3.5$ bar) and only a little area is submitted to conditions leading to filtration at critical flux (associated to the critical TMP, $\mathrm{TMP}_{\text {critical }}=1.5 \mathrm{bar}$ ).

Even if the impact of the pressure drop and of the turbulences due to spacers on the local fouling/cleaning is commonly suggested, experimental investigations remain particularly difficult to hold in order to confirm this assumption and mainly global observations are commonly available, except those from NMR studies dealing only with quite thick fouling whereas in the case of skim milk UF the irreversible fouling layer is equal or lower than one micrometre.

This paper aims at evidencing how the knowledge of the distribution of a very thin layer of irreversible fouling can help to go ahead in the understanding of the fluid circulation in a 
spiral membrane. The membrane destruction for analysis of fouling due to proteins quantitatively determined by mean of FTIR-ATR is an integrant part of the approach together with the characterisation of local hydrodynamic using UF experiments performed in small plate and frame module working in dedicated conditions.

\section{EXPERIMENTAL}

\subsection{Solutions}

The skim milk used is a commercial one (UHT, Lait de Montagne, Carrefour, France) containing an average of 32 g.L.- proteins and 48 g.L. ${ }^{-1}$ carbohydrates (mainly lactose) and only tracks of lipids $(<0.5 \%)$.

Water used either for solution preparation and membrane rinsing is deionised and $1 \mu \mathrm{m}$ filtered. Its conductivity is always lower than $1 \mu \mathrm{S} . \mathrm{cm}^{-1}$

\subsection{Membrane and ultrafiltration loops}

\subsubsection{Membrane material and membrane preparation}

A PES membrane (5-10 $\mathrm{kg} \mathrm{mol}^{-1}$, HFK-131, Koch, USA) is selected because it is the worldwide reference for the skim milk UF application at industrial scale. At laboratory scale the spiral module is chosen in order to have a filtering area of several square meters $\left(6.5 \mathrm{~m}^{2}\right.$, 4333 K131 VYV module). It can be noticed that according to their date of acquisition, the spiral membranes, are made of 3 double sheets of membranes (old version, bought in 2003, membrane reference KM8243083017V, corresponding to the spiral membrane used here for skim milk UF) then they are made of 4 double sheets of membranes (new version buy after 2006, corresponding to source of flat membranes used in this study, see below).

\section{- Spiral membrane:}

The spiral membrane (old version, called CIP-1, 2003) used for UF of skim milk is installed on the UF pilot of our laboratory since December 2003. It is regularly checked that the membrane permeability to water at $50^{\circ} \mathrm{C}$ remains constant at $50 \pm 5 \mathrm{~L} \cdot \mathrm{h}^{-1} \cdot \mathrm{m}^{-2} \cdot \mathrm{bar}^{-1}$ and that the permeability in skim milk remains constant at $15 \pm 1 \mathrm{~L}^{-1} \mathrm{~h}^{-1} \cdot \mathrm{m}^{-2} \cdot \mathrm{bar}^{-1}$ at $50^{\circ} \mathrm{C}$. This 
membrane has been regularly cleaned, mainly with alkaline detergents at $\mathrm{pH}$ 11.5-12.0. During the 9 years of its service life, the cleaning time by alkaline bleach at $200 \mathrm{ppm}$ in total free chlorine has been negligible thus limiting the chemical ageing of the membrane material. Between each UF, the membrane has been stocked in sodium metabisulfite $\left(5\right.$ g. $\left.\mathrm{L}^{-1}\right)$ to avoid micro-organisms growth. Even if the permeability to water remains always correct, we have autopsied the membrane, to understand its fouling behaviour.

\section{- Flat membranes:}

Several flat membranes of $127 \mathrm{~cm}^{2}$ filtering area and spacers (V type, $1 \mathrm{~mm}$ thickness) are sampled in a second virgin spiral membrane of the same reference as described above (new version commercialised after 2006). A new flat membrane is used for each experiment and is firstly rinsed with warm water to remove the preservative and then inserted in a plate and frame module. Secondly a procedure of compaction is applied to reach a stable water flux. The compaction step consists in UF of deionised water during $6 \mathrm{~h}$ at $50^{\circ} \mathrm{C}$ applying an increasing TMP from 1 to 4 bar. The permeability to water is measured on all flat membranes. We have observed that the water flux of the flat membrane depends on the location of the membrane coupon in the spiral membrane. Figure 1 highlights this phenomenon, evidencing that the flux is greater in the spiral sheet centre and can be very low on the sides (especially near the glue, our hypothesis is that this difference in the heterogeneousness of the membrane permeability could be partly attributed to the diffusion of the glue on the edges of the membrane together with heterogeneity of the membrane material itself due to its fabrication process, but experiments are needed to confirm this assumption). This allows establishing mapping of the permeability distribution in a virgin spiral membrane. As shown on Figure 1 the variation on the membrane permeability can be $10 \%$ or $20 \%$ depending on the sheet in the same spiral membrane.

A similar procedure was punctually applied to another virgin spiral membrane allowing confirming the general trends in the description of the permeability distribution and up to $50 \%$ variation can sometimes be observed.

\subsubsection{UF with the spiral membrane}

The spiral membrane is installed on a pilot provided by TIA (TIA 3093, Bollène, France) shown on Figure 2. The two pumps impose a cross-flow velocity close to $0.37 \mathrm{~m} \cdot \mathrm{s}^{-1}$ (see 
Appendix 1) in the recirculation loop thanks to the $10.5 \mathrm{~m}^{3} \cdot \mathrm{h}^{-1}$ flow rate.

In such configuration, the feed is introduced perpendicularly to the membrane axis and against a sharp right angle provoking turbulences in the carter. Nevertheless the membrane entrance is few centimetre after this angle and a stable regime is probably established before the membrane entrance (Figure 2, Figure 3).

The average TMP is classically calculated as the mean value when considering the membrane inlet TMP and the membrane outlet TMP. Nevertheless, it must be kept in mind that the pressure drop along the membrane element is 2.2 bar that is not a negligible value by comparison to the average TMP (see below).

Fouling of the PES membrane is achieved by UF of skim milk during $3 \mathrm{~h}$ at $50^{\circ} \mathrm{C}$ in batch mode, meaning here that both the retentate and the permeate are fully recycled in the feed tank. This corresponds to a volume reduction ratio (VRR) of 1. Because of the dead volume of the pilot, $24 \mathrm{~L}$ is the minimum volume to be processed to allow filtration without any vortex in the feed tank and some sampling. Several TMPs ranging from 1 to 4 bar can be applied (see results). The membrane flux $\left(\mathrm{J}_{\mathrm{UF}}\right)$ is followed all over the skim milk UF. The irreversible part of the fouling is evaluated from the water flux measurement $\left(\mathrm{J}_{\text {irrev,initial }}\right)$ after a careful water rinsing.

\subsubsection{UF with the flat membranes}

The plate and frame module (Ray-Flow X100, Novasep-Process, France) allows using two membranes in series. Two new membranes $\left(2 \times 127 \mathrm{~cm}^{2}\right)$ are used for each experiment. After the compaction procedure, the water flux $\left(\mathrm{J}_{0}\right)$ is further used as reference for the pristine membrane.

Fouling of two PES membranes is simultaneously achieved by UF of skim milk during $3 \mathrm{~h}$ at $46^{\circ} \mathrm{C} \pm 1{ }^{\circ} \mathrm{C}$ in batch mode. Because of the dead volume of the pilot, the skim milk volume used is the minimum one, equal to $4 \mathrm{~L}$. The average cross flow velocity is $\mathrm{v}=0.34 \mathrm{~m} \cdot \mathrm{s}^{-1}$ and spacers are added in the liquid channel, in order to be, as close as possible, in the same hydrodynamic conditions as with the spiral membrane. Various TMPs ranging from 1 to 4 bar are applied (see results) and the membrane flux $\left(\mathrm{J}_{\mathrm{UF}}\right)$ is followed all over the skim milk filtration.

Then membranes are carefully rinsed with deionised water and the final water flux ( $\left.\mathrm{J}_{\text {irrev, initial }}\right)$ is determined for both membranes, evidencing the good agreement between the two membrane behaviors. 
Resistances due to membrane and fouling (both overall and irreversible one remaining after water rinsing) are determined from the well-known resistance in series model.

\subsubsection{Determination of the limiting and critical/threshold fluxes}

The protocol used has been already described in [3] for the spiral membrane and adapted for the flat membrane as described in [15]. Some details are briefly repealed here for sake of clarity. Permeate fluxes are measured during skim milk UF by increasing step by step the TMP from 1 to 4 bar (Figure 4). The permeate flux at plateau value corresponds to the limiting flux ( $\mathrm{J}_{\text {limiting }}$ ) and in the following the (TMP limiting, $\mathrm{J}_{\text {limiting }}$ ) point is determined as the first point for which the plateau value of flux is reached. The critical/threshold point is determined from the shape of the J vs TMP curve: the relationship remains linear below the ( $\mathrm{J}_{\text {critical/threshold }}, \mathrm{TMP}_{\text {critical/threshold }}$ ) point allowing its determination. It is noticeable that without retentate spacers in the liquid channel, the limiting flux is quite immediately reached highlighting the role of local turbulences due to the presence of spacers when the cross-flow velocity is so low that only a laminar regime is established from the fluid circulation.

\subsubsection{Quantification of residual proteins on membranes}

We have previously shown that the irreversible fouling is only made of proteins as we have not been able to show the presence of other compounds on the membrane $[1,2]$. Consequently, the fouling seems to be valuably appreciated from the protein quantification that can be achieved by an infra-red technique according to a procedure established in our laboratory [18] and previously described in $\left[\mathbf{1 , 2}\right.$. The calibration range is $1-350 \mu \mathrm{g} . \mathrm{cm}^{-2}$.

Infra-red (FTIR) analyses are performed using the Attenuated Total Reflection mode (ATR) directly on fouled membranes. The FTIR-ATR spectra are recorded between 4000 and 600 $\mathrm{cm}^{-1}$ with a spectrometer provided by Perkin-Elmer (Paragon 1000, spectrum for windows software) equipped with a ZnSe crystal with an incidence angle of $45^{\circ}$ allowing 12 reflections. The background spectrum is recorded in the air. The conditions of acquisition are as follows: 20 scans, $2 \mathrm{~cm}^{-1}$ resolution. The membrane samples are carefully dried under dynamic vacuum before registration. 
Two specific procedures are used: one for the flat fouled membranes and the other for the spiral fouled membrane.

\section{- Specific procedure for the flat membranes}

To take into account possible variations of the irreversible fouling amount due to small variations of the velocity profile in the plate and frame module [2] an average value is calculated from the quantification of the fouling deposit measured on nine equivalent pieces cut in the membrane. Generally the difference does not exceed $3 \mu \mathrm{g} . \mathrm{cm}^{-2}$ between the 9 samples of a $127 \mathrm{~cm}^{2}$ membrane coupons. As two flat membranes are simultaneously fouled on the plate and frame module, it has been preliminary checked that the average amount of proteins are similar for the two membranes in series.

\section{- Specific procedure for the spiral membrane}

The spiral membrane after fouling by skim milk and rinsing by deionised water can also be analyzed. This procedure can only be one time applied at the end of the overall study. It can be underlined that the limitation is only due to economic considerations and time consumption and not because of technical aspects. The overall spiral membrane $\left(6.5 \mathrm{~m}^{2}\right)$ is cut in 336 pieces of $127 \mathrm{~cm}^{2}$ area. Only the center of each sample is analyzed by FTIR-ATR for quantification purpose (of course each sample could be divided in 9 smaller pieces as for the flat membranes, but it has been checked that the variations were not very different and a single result seems quite acceptable for the followed purpose). This autopsy allows establishing a mapping of the irreversible fouling that would be compared to the fouling amount obtained for the flat membranes at various TMPs (see results and discussion). 


\section{RESULTS AND DISCUSSION}

\subsection{Fouling}

\subsubsection{Hydraulic characterisation}

The limiting and critical points are determined either with the flat and spiral membranes. It has been checked that in both cases the critical TMP is 1.5 bar whereas the limiting TMP is 3.5 bar.

Then UF has been performed at constant TMP values including $\mathrm{TMP}_{\text {critical }}$ and $\mathrm{TMP}_{\text {limiting, }}$, but also an intermediate value of 2.0 bar. A fourth value greater than $\overline{\mathrm{TMP}}_{\text {limiting }}$ is also tested, namely 4.0 bar. Table 1 summarizes the resistances due to the overall fouling $\left(\mathrm{R}_{\mathrm{f}}\right)$ for the set of experiments. $\mathrm{R}_{\mathrm{f}}$ can be considered as roughly constant from 1.5 bar to 4.0 bar, regardless of the membrane geometry.

For a given TMP of fouling and after water rinsing, the remaining fouling resistance $\left(\mathrm{R}_{\text {irrev,initial }}\right)$ is roughly the same for both flat and spiral membranes, even if it seems to slightly increase with the TMP increase in this last case. More or less, $35 \%$ of the fouling is irreversible in the 1.5-4.0 bar TMP range.

Finally, on a global hydraulic point of view, fouling obtained with the two membranes geometries can be considered as similar.

\subsubsection{Physico-chemical characterisation}

Table 2 shows the residual amount of proteins after fouling of flat membranes obtained at constant TMP ranging from 1.5 to 4.0 bar and after water rinsing. Contrary to hydraulic characterisation, this quantification highlights differences according to the TMP. The protein amount at 1.5 bar (critical TMP) is about half that obtained for higher TMPs.

Similar quantifications are performed on the spiral membrane fouled at an average TMP of 2.6 bar (3.7 bar inlet and 1.5 bar outlet). This spiral membrane is made of 3 sheets of membrane corresponding to 6 different flat membranes assembled by two, back to back (Figure 3, Figure 5).

Figure 6 shows the distribution of the residual protein amount according to the location on the six membranes issued from the autopsied fouled spiral membrane. At first sight, 
regardless of the membrane, the zone in close vicinity to the permeate collector axis is always the most fouled one. The other parts of the membranes are heterogeneously fouled.

In a first attempt of simplification, an average value is calculated representing $85 \%$ of the membrane area (except values in close vicinity to the collector axis), that corresponds to $40 \pm$ $20 \mathrm{g.cm} \mathrm{cm}^{-2}$ and (Figure 7).

The fouling can also be discussed with more accuracy. For instance, considering an average TMP of 2.6 bar, the expected amount of the residual fouling calculated from the flat membrane experiments would be close to $22 \mu \mathrm{g} . \mathrm{cm}^{-2}$ (Table 2) that is half of the average value calculated above. Figure 6 and Figure 7 show clearly that some zones of the spiral membrane are fouled with this protein amount but some others are much more fouled.

In order to propose a more accurate analysis of the irreversible fouling distribution in the spiral membrane, attempt of correlation with the local TMP would be interesting. As no local measurement can be available, an attempt of calculation is made. On an experimental point of view the pressure drop on the retentate side is measured at 2.2 bar. It can be reasonably assumed that the pressure drop is linear along the membrane length (that must be understood as parallel to the direction of the permeate axis, in other words the axial direction, Figure 5b). As permeate side is opened to air (and then set at atmospheric pressure), the variation of the permeate pressure with the location on membrane ean be is neglected at first sight. Nevertheless, it is probable that some variations also occurred with respect to the membrane wounding and the presence of permeate spacers that are able to generate some turbulences and consequently a pressure drop. It can be guessed that near the permeate axis the pressure is that of atmosphere but at the end of each sheet the pressure could be greater (Figure 5c, Figure 5d). Consequently the TMP is probably a little overestimated in our approach for the zones far from the permeate axis.

This hypothesis leads to the assumption that firstly TMP mainly depends on the position along the collector axis (feed flow direction, axial dimension) and then decreases from the inlet to the outlet. Secondly, it is considered that for a given distance from the membrane inlet (feed flow direction along the permeate axis) the TMP variation with the distance (d, Figure 7) from the permeate axis is negligible (in other words the radial dimension, Figure 5c and Figure 5d). It is then inferred that the spiral membrane can be divided in four main zones of TMP, defined by reference to the $127 \mathrm{~cm}^{2}$ samples that will be cut in the membrane for 
autopsy purpose and corresponding to "local" TMP values (at sample centre) of 3.5, 3.0, 2.5 and 2.0 bar, respectively (Figure 6). An average of protein amount is then determined for each "local" TMP (Table 2). In the spiral module the same protein average amount is obtained for TMP in the range 2.0 to 3.5 bar that is in good agreement with experiments on flat membrane. But, it is also observed that the level of the irreversible fouling is significantly higher in the spiral membrane than with the flat one for the same TMP range.

Looking carefully at the quantification of the protein amount in the spiral membrane, a fouling distribution can be observed for a given average local TMP on a single membrane sheet (Figure 6). All membrane sheet demonstrate different fouling amount. The possible origins of this fouling distribution are discussed below.

\subsubsection{Discussion on the possible origin of fouling distribution}

Different hypotheses can be made to explain these differences either based on the initial membrane material heterogeneity and on the variable local hydrodynamic conditions.

\subsubsection{1 . Heterogeneity of the virgin membrane permeability}

The heteregoneity of the membrane material is observed from water permeability measurements performed on several membrane pieces that are sampled in a spiral virgin membrane (Figure 1). Similar trends are observed for all sheets of this spiral membrane and on all sheets of a second spiral membrane (not shown here). In our laboratory we performed such measurements systematically from more than six years now, and finally, the permeability is generally higher in the spiral membrane center, in other words far from the edges where is applied the glue between two membranes of a same double sheet.

It can be noticed that FTIR-ATR spectrum of membrane (active layer side) allows to demonstrate the presence of glue at membrane edges (superimposition of FTIR spectra of PES and additives containing $\mathrm{C}=\mathrm{O}$ bound that could correspond to polyurethane glue type). We guess that the membrane permeability is probably decreased by the diffusion of the glue from the edges toward the center, but we have failed to prove its presence on the active layer side when going away from the center. Another explanation could be the heterogeneity of the active layer thanks to the process achieved to obtain polymer large sheets.

Nevertheless, permeability in skim milk is always the same regardless of the initial water permeability of the membrane coupon. So in the following we suggest to ignore this 
assumption as a possible main origin of fouling variation.

\subsubsection{2 . TMP gradient in the spiral membrane}

The second hypothesis to explain the heterogeneity of the irreversible protein amount on the spiral membrane is linked to the TMP variation as discussed in the following.

Generalising results obtained with the flat membranes at various TMPs (Table 2), we can consider that all TMPs higher than the critical TMP might lead to the same fouling amount. Because of the pressure drop, the center of all pieces sampled in the spiral membrane (location of the protein quantification) are in the $2.0-3.5$ bar range, corresponding to a TMP range higher than the critical TMP (1.5 bar). Nevertheless a small part of the membrane outlet is set at the critical TMP and is probably fouled in a lower extend but this phenomenon can be considered as negligible for this particular membrane.

Consequently the variation of the fouling amount from the inlet to the outlet at a given distance from the permeate collector axis (radial dimension, Figure 8) cannot be mainly attributed to the TMP variation and the main origin must be found elsewhere.

\subsubsection{3 . Gradient of velocity/turbulences in the spiral membrane}

The third hypothesis to explain the heterogeneity of the irreversible protein amount on the spiral membrane is linked to the fluid distribution and fluid velocity/turbulences in this quite complex geometry. Of course, as the filtered fluid is newtonien, it is not compressible. So in abscence of local turbulences, the fluid velocity must remain constant along the membrane length. But to avoid a very important fouling, lowering the process productivity, retentate spacers are added in the liquid channel to promote local turbulences. The result would be the creation of a local field of velocity/turbulences.

It can be underlined that up to now computational fluid dynamic (CFD) is not able to propose theoretical approach of the fluid velocity profile in a whole spiral membrane and calculations are mainly achieved in close vicinity of a single cross of the retentate spacers, as seen above. Even though, the validation of theoretical proposal will always be a need. The mapping of fouling has been shown to be an experimental way to study the velocity field in the case of a flat membrane inserted in a plate and frame module, by comparing the fouling amount and the velocity gradient calculated from CFD [2]. This methodology has also been validated to discuss the shear stress in dynamic filtration with circular membrane inserted on a V-Sep 
vibrating module [2]. These experimental results are in good accordance with some NMR observations achieved on a whole spiral membrane fouled by micro-organisms leading to a biofilm (in this case the fouling layer was very thick contrary to the thickness of the irreversible deposit of proteins of the present study) [9-12].

The discussion proposes here is in the continuity of the experimental approch described in [2]. Considering a given distance from the permate axis ( $\mathrm{d}$, radial dimension), the fouling varies from the inlet to the outlet but it is not in a continuous trends (Figure 8a). Generally in a first section (further called zone A) the fouling at inlet is greater than the fouling at outlet, then the fouling is roughly the same at inlet and outlet of the membrane (Zone B), finally the fouling is systematically higher at outlet than at inlet (Zone C) (Figure 8b).

From one membrane to another, the size of each three zones varies as shown in Table 3. Nevertheless as first attempt we can considered that zone A corresponds to the first $300 \times 10^{-3}$ $\mathrm{m}$, zone $\mathrm{B}$ to the $300 \times 10^{-3-} 1000 \times 10^{-3} \mathrm{~m}$ range and zone $\mathrm{C}$ to the last part of the unwounded membrane in the $1000 \times 10^{-3}-1200 \times 10^{-3}$ m range. The 3 zones $(\mathrm{A}, \mathrm{B}, \mathrm{C})$ are schematically shown Figure 9. For the most inner membrane sheet (F1C1), zone A corresponds more or less to the two first turns of the membrane in the wound, zone B to the 3 and 4 turns plus part of turn number 5 , whereas zone $\mathrm{C}$ corresponds to the last part of turn 5 and to turn 6 . Similar drawn can be established for the other membrane sheets and clearly the three zones are not correlated to the upper or lower positions in the carter toward fluid entrance.

Considering that the lower the fouling is the higher velocity/turbulences are, it can be drawn that (i) in zone A, velocity/turbulences increase from inlet to outlet, (ii) in zone B, there is no significant variation of velocity/turbulences from inlet to outlet, (iii) in zone C, velocity/turbulences decrease from inlet to outlet.

Nevertheless, if similar trends are shown, our results also highlight the difference in local fluid distribution from one membrane sheet to another, as fouling level is different from one membrane to another. Li et al. [20] have proposed an interesting discussion about the curvature effect of the spacer in a spiral membrane. They finally suggest to optimize the design of the spiral module by varying that of the spacers from one feed channel to another, aiming at the decrease of the imbalance shear stress between the inner and outer membrane walls. We agree with such proposals. If such module could be fabricated, the fouling mapping we proposed in this paper would be a way to experimentally establish the proof of concept. 


\section{CONCLUSION}

The approach discussed in this paper aims at show that analysis of a thin layer of irreversible fouling in a spiral membrane, each zone of which filtering in conditions over the critical one, is a powerful approach to deal with the role of the velocity/turbulences independently of the transmembrane pressure gradient. Considering that the lower the fouling is the higher the velocity/turbulences are, it can be drawn that the $6.5 \mathrm{~m}^{2}$ membrane studied here made of three double sheets of membrane can be roughly described from only one sheet. Each sheet can be divided in 3 zones having more or less the same size when comparing one sheet to another. These zones are defined according to their distance toward the permeate collector axis (radial dimension) and not regarding the position according to inlet or outlet of the spiral element (axial dimension). Fouling amount suggests that the velocity/turbulences are constant in the main middle part of the membrane (zone B, $50 \%$ of the global area). But for the area in close vicinity to the permeate axis, and corresponding to $30 \%$ of the whole membrane (zone A), the fouling decreases from inlet to outlet meaning that velocity/turbulences increase. On the contrary, for the area far from the permeate axis and corresponding to the last $20 \%$ of the membrane (zone C) the fouling increases from inlet to outlet meaning that velocity/turbulences decrease. Differences between the behaviors of zone A and zone $\mathrm{C}$ could perhaps be related to an additional gradient of centrifuge forces. To go ahead, a similar study applied to several a spiral membranes of same area but made of four double sheets of membranes instead of three in the present case is in progress, also taking into account other TMP gradient ranges applied to the filtering area.

Moreover, in order to have a better insight, we need now to establish a correlation between the fouling amount and controlled velocity/turbulences in order to appreciate the real gradient in a more accurate way. A first limitation is already observed depending on the membrane material itself, as irreversible fouling clearly increases with membrane ageing [19] and consequently the age of the membrane material must be carefully mastered in addition to the control of hydrodynamics. This work is also currently in progress.

\section{Acknowledgements}

This study was financially supported by the "Region Bretagne" (Brittany) program DURAMEM for the PhD grant of NWD, France. 


\section{References}

[1] M. Rabiller-Baudry, L. Bégoin, D. Delaunay, L. Paugam, B. Chaufer, A dual approach of membrane cleaning based on physico-chemistry and hydrodynamics: Application to PES membrane of dairy industry, Chem. Eng. Process. 47 (2008) 267-275.

[2] D. Delaunay, M. Rabiller-Baudry, J.M. Gozalvez-Zafrilla, B. Balannec, M. Frappart, L. Paugam, Mapping of protein fouling by FTIR-ATR as experimental tool to study membrane fouling and fluid velocity profile in various geometries and validation by CFD simulation, Chem. Eng. Process. 47 (2008) 1106-1117.

[3] H. Bouzid, M. Rabiller-Baudry, L. Paugam,F. Rousseau, Z. Derriche, N.E. Bettahar, Impact of zeta potential and size of caseins as precursors of fouling deposit on limiting and critical fluxes in spiral ultrafiltration of modified skim milks, J. Membr. Sci. 314 (2008) 6775.

[4] J.L.C. Santos, V. Geraldes, S. Velizarov, J.G. Crespo, Investigation of flow patterns and mass transfer in membrane module channels filled with flow-aligned spacers using computational fluid dynamics (CFD), J. Membr. Sci. 305 (2007) 103-117.

[5] M. Rahimi, S.S. Madaeni, M. Abolhasani, A. A. Alsairafi, CFD and experimental studies of fouling of a microfiltration membrane, Chem. Eng. Process. 48 (2009) 1405-1413.

[6] Y.L. Li, K.L. Tung, CFD simulation of fluid flow through spacer-filled membrane module: selecting suitable cell types for periodic boundary conditions, Desalination 233 (2008) 351-358.

[7] J. Schwing, D.E. Wiley, D.F. Fletcher, A CFD study of unsteady flow in narrow spacerfilled channels for spiral-wound membrane modules, Desalination 146 (2002) 195-201.

[8] Y.L. Li, K.L. Tung, Y.S. Chen, K.J. Hwang, CFD analysis of the initial stages of particle deposition in spiral-wound membrane modules, Desalination 287 (2012) 200-208.

[9] D.A. Graf von der Schulenburg, J.S. Vrouwenvelder, S.A. Creber, M.C.M. van Loosdrecht, M.L. Johns, Nuclear magnetic resonance microscopy studies of membrane biofouling, J. Membr. Sci. 323 (2008) 37-44.

[10] S.A. Creber, J.S. Vrouwenvelder, M.C.M. van Loosdrecht, M.L. Johns, Chemical cleaning of biofouling in reverse osmosis membranes evaluated using magnetic resonance imaging, J. Membr. Sci. 362 (2010) 202-210.

[11] S.A. Creber, T.R.R. Pintelon, D.A.W. Graf von der Schulenburg, J.S.Vrouwenvelder, M.C.M. van Loosdrecht, M.L. Johns, Magnetic resonance imaging and 3D simulation studies of biofilm accumulation and cleaning on reverse osmosis membranes, Food Bioproducts Process. 88 (2010) 401-408.

[12] S. A. Creber, T. R.R. Pintelon, M. L. Johns, Quantification of the velocity acceleration factor for colloidal transport in porous media using NMR, J. Colloid Interface Sci. 339 (2009) $168-174$. 
[13] J.S. Vrouwenvelder, C. Picioreanub, J.C. Kruithofa, M.C.M. van Loosdrechtb, Biofouling in spiral wound membrane systems: Three-dimensional CFD model based evaluation of experimental data, J. Membr. Sci. 346 (2010) 71-85.

[14] J.S. Vrouwenvelder, D.A. Graf von der Schulenburg, J.C. Kruithof, M.L. Johns, M.C.M. van Loosdrecht, Biofouling of spiral wound nanofiltration and reverse osmosis membranes: a feed spacer problem, Water Research 43 (2009) 583-594.

[15] Diagne N.W., Rabiller-Baudry M., Paugam L. On the actual cleanability of polyethersulfone membrane fouled by proteins at critical or limiting, J. Membr. Sci. 425 (2012) 40-47.

[16] R.W. Field, D.X. Wu, J.A. Howell, B.B. Gupta, Critical flux concept for microfiltration fouling, J. Membr. Sci. 100 (1995) 259-272.

[17] R.W. Field, G.K. Pearce, Critical, sustainable and threshold fluxes for membrane filtration with water industry applications, Adv. Colloid Interface Sci. 164 (2011) 22-38.

[18] M. Rabiller-Baudry, F. Gouttefangeas, J. Le Lannic, P. Rabiller, Coupling of SEM_EDX and FTIR-ATR to (quantitatively) investigate organic on porous organic composite membranes, Chapter in Current microscopy contributions to advances in science and technology, (2012), Ed Méndez-Vilas, Formatex, Badajoz Spain.

[19] M. Rabiller-Baudry, C. Leperoux, D. Delaunay, H. Diallo, L. Paquin, On the use of microwaves to accelerate ageing of an ultrafiltration PES membrane by sodium hypochlorite to obtain similar ageing state to that obtained for membranes working at industrial scale, Filtration 14 (1) (2014) 38-48.

[20] Y.L. Li, K.L. Tung, M.Y. Lu, S.H. Huang, Mitigating the Curvature Effect of the SpacerFilled Channel in a Spiral-Wound Membrane Module, J. Membr. Sci. 329 (2014) 106-118. 
Appendix 1 - Estimation of the cross-flow velocity in the spiral membrane

Figure A1 describes the unwounded spiral membrane as an equivalent rectangle of the same area as the whole spiral membrane. This membrane is made of 3 double sheets of membrane

- Length of permeate axis is $84 \mathrm{~cm}$

- Membrane area is $6.5 \mathrm{~m}^{2}$

- Membrane modelized as a rectangle of $6.5 \mathrm{~m}^{2}$ (allowing the determination of L)

- Area $=84 \times 10^{-2} \times \mathrm{L}=6.5 \rightarrow \mathrm{L}=7.74 \mathrm{~m}$

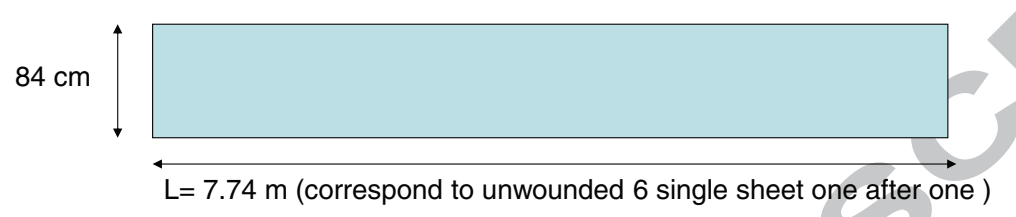

Figure A1 : Equivalent rectangle of the unwounded spiral membrane of $6.5 \mathrm{~m}^{2}$.

Then two assumptions are considered to model the membrane.

Hypothesis 1: In the spiral membrane the feed flow is equally distributed along the surface seen at entrance. In other terms the feed see the whole L length at membrane entrance (Figure A2)

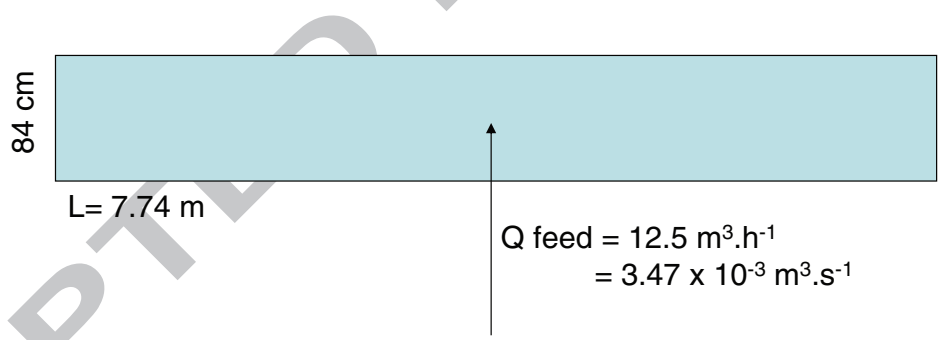

Figure A2: Hypothesis of equal distribution of fluid at spiral membrane entrance

Hypothesis 2: The thickness of the liquid channel is that of the retentate spacer as the spiral membrane is very compact. Consequently, the area in which the fluid is distributed is a small rectangle (Figure A3). Then Area $=1 \mathrm{~mm} \times 7.74 \mathrm{~m} \rightarrow 7.74 \times 10^{-3} \mathrm{~m}^{2}$

Consequently, the cross-flow velocity $\mathrm{v}=$ Qfeed $/$ area $=2.92 \times 10^{-3} / 7.74 \times 10^{-3}=0.37 \mathrm{~m} . \mathrm{s}^{-1}$

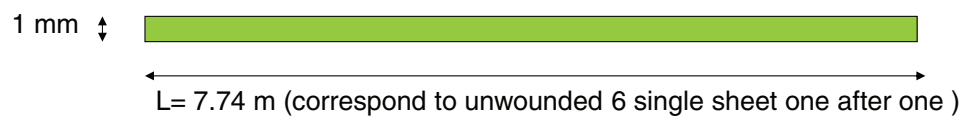

Figure A3: Hypothesis on the thickness of the liquid channel in the spiral membrane 


\section{Figure captions}

Figure 1: Evidencing of the distribution of the permeability to water at $50^{\circ} \mathrm{C}$ on two sheets $(a$ and $b$ ) of a same virgin 4333 spiral membrane (this behaviour is representative of all sheets for which we have performed such measurements in different spiral membranes having 3 or 4 sheet. Flux measurements are performed on flat membranes of $127 \mathrm{~cm}^{2}$ filtering area sampled in the different sheets.

Figure 2. Scheme of the UF pilot equipped with the 4333 spiral membrane allowing the feed entrance in the carter first perpendicularly to the membrane axis.

Figure 3. Pictures of the spiral membrane of this study - (a) inserted in the stainless steel carter on the pilot - (b) evidencing the distribution system at outlet of the spiral membrane.

Figure 4 - Typical UF of skim milk at $46^{\circ} \mathrm{C}, V R R=1,0.34 \mathrm{~m} \cdot \mathrm{s}^{-1}$ with step by step increase of TMP for a flat membrane inserted in the plate and frame module with $(\bullet)$ or without retentate spacers of $1 \mathrm{~mm}$ inserted in the liquid channel.

Figure 5. Schemes of a spiral membrane (a) with 3 double sheets highlighting the different channels in which are inserted retentate or permeate spacer, respectively. Each membrane is labelled according to the same nomenclature as those used for the quantification of protein amount for the autopsied membrane. F1C1 is the innermost membrane whereas F3C2 is the outermost one - (b) single sheet made of two membranes glued back to back and direction of feed flow- (c) single sheet of membrane and direction of permeate when crossing the membrane $-(d)$ single sheet of membrane and direction of permeate moving toward the permeate axis in the permeate channel shared by two membranes glued by to back.

Figure 6. Mapping of the protein irreversible deposit in the spiral membrane determined from FTIR-ATR quantification (protein amount in $\mu \mathrm{g} . \mathrm{cm}^{-2}$ ) according to the location in the spiral membrane. The local TMP is calculated from the assumption of a linear pressure drop decrease. The membrane labels are defined on Figure 5. $(n d=$ not determined)

Figure 7. Irreversible amount of proteins on the spiral membrane versus the distance from the permeate collector axis (at a given distance each point correspond to a local TMP for the 6 membrane sheets). The estimation of the local average TMP is calculated from TMP at inlet and outlet and assuming a linear decrease of the pressure drop of 2.2 bar along the spiral membrane element. 
Figure 8 : Amount of protein irreversible deposit on the spiral membrane versus the distance from the permeate collector axis for inlet $(\diamond$ local TMP $=3.5$ bar) and outlet $(\times$, local TMP = 2.0 bar) samples. (a) All membranes - (b) F1C2 membrane (see Figure 5 for definition). The estimation of the local average TMP is calculated from TMP at inlet and outlet and assuming a linear decrease of the pressure drop along the spiral membrane element.

Figure 9: The 3 zones A, B, C (defined Table 3) on a membrane sheet and variation of fouling from which is deduced variation of velocity/turbulences 


\section{Figures}

\begin{tabular}{|c|c|c|c|}
\hline & permeate & tube & \\
\hline & 110 & 113 & 95 \\
\hline & 107 & 109 & 93 \\
\hline & 114 & 115 & 97 \\
\hline 97 & 111 & 112 & 99 \\
\hline 101 & 127 & 123 & 102 \\
\hline 104 & 120 & 118 & 101 \\
\hline 97 & 119 & 120 & 97 \\
\hline \multirow[t]{4}{*}{99} & 113 & 114 & 94 \\
\hline & 108 & 109 & 99 \\
\hline & 94 & 97 & 94 \\
\hline & 87 & 88 & 96 \\
\hline
\end{tabular}

average standard deviation RSD (\%)

(a) one sheet (F1C2)

\begin{tabular}{|c|c|c|c|}
\hline \multicolumn{4}{|c|}{ permeate } \\
\hline & & & \\
\hline 128 & 179 & 180 & 133 \\
\hline & 178 & 173 & \\
\hline 125 & 164 & 176 & \\
\hline 121 & 184 & 200 & \\
\hline & 186 & 241 & \\
\hline & 199 & 221 & \\
\hline & 201 & 202 & \\
\hline & & & \\
\hline & 231 & 270 & \\
\hline & 212 & 218 & \\
\hline
\end{tabular}

average

standard deviation

187

RSD (\%)

(b) another sheet (F2 C1)

Figure 1: Evidencing of the distribution of the permeability to water at $50^{\circ} \mathrm{C}$ on two sheets (a and $b$ ) of a same virgin 4333 spiral membrane (this behaviour is representative of all sheets for which we have performed such measurements in different spiral membranes having 3 or 4 sheet. Flux measurements are performed on flat membranes of $127 \mathrm{~cm}^{2}$ filtering area sampled in the different sheets. 


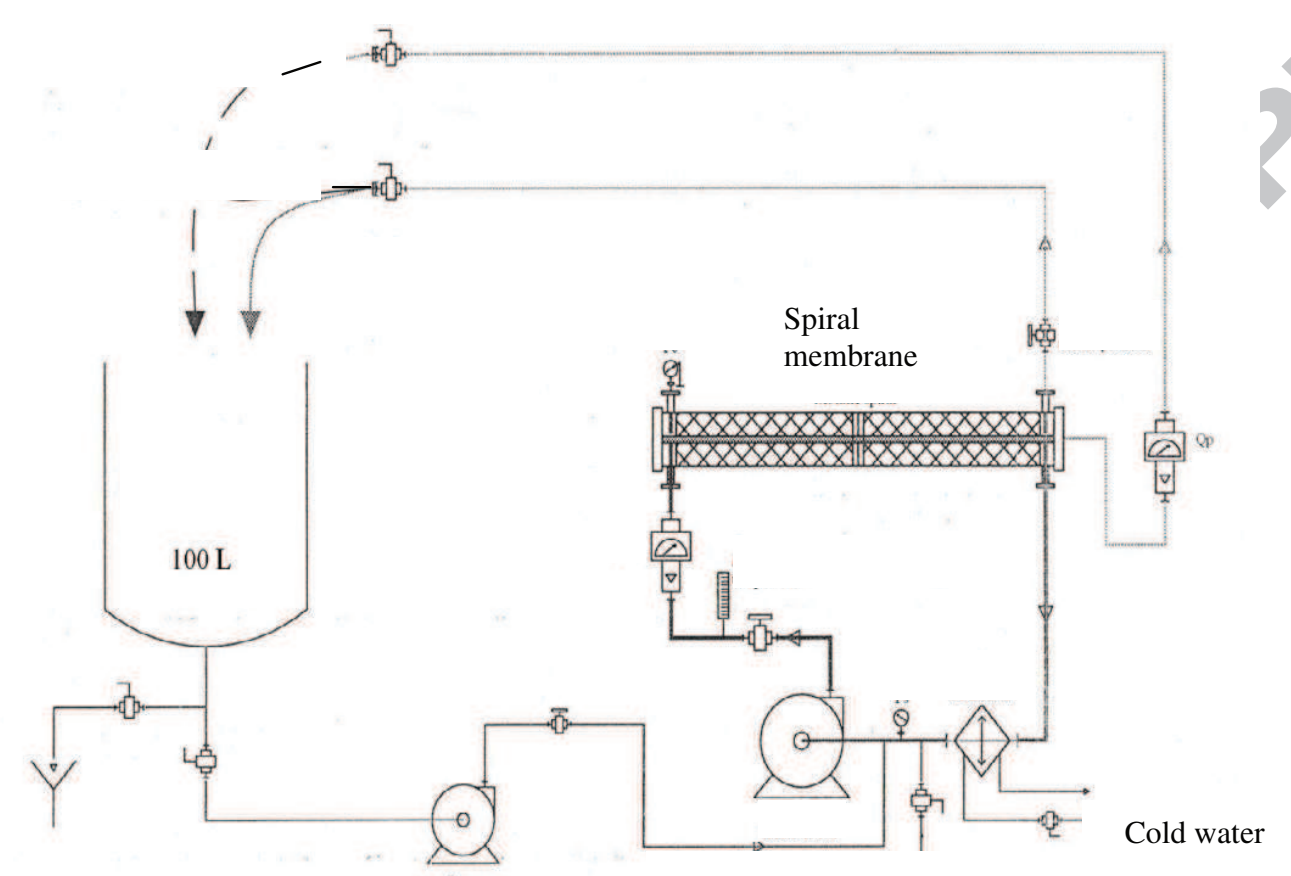

Figure 2. Scheme of the UF pilot equipped with the 4333 spiral membrane allowing the feed entrance in the carter first perpendicularly to the membrane axis. 


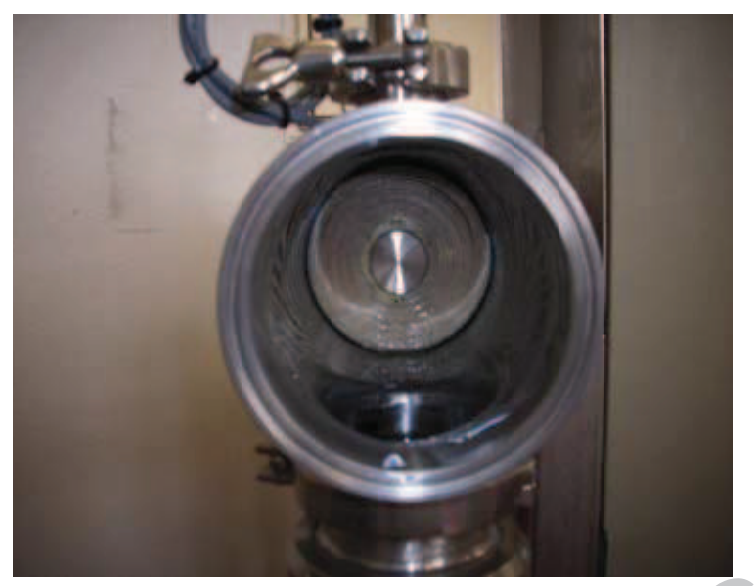

(a)

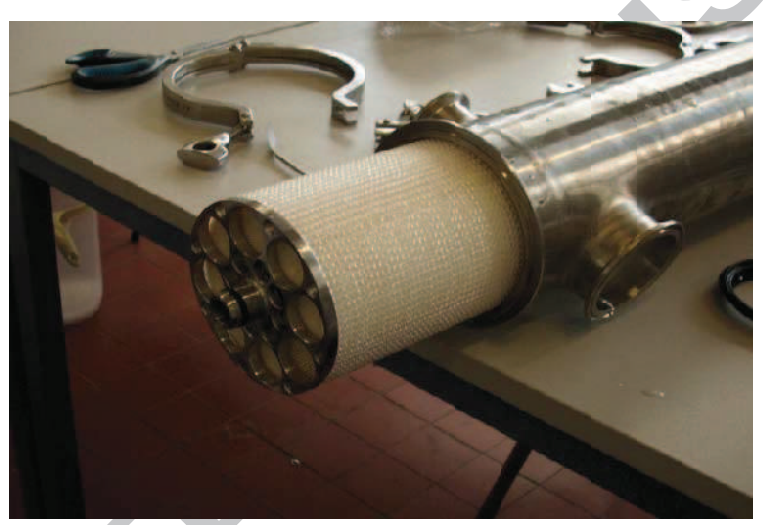

(b)

Figure 3. Pictures of the spiral membrane of this study - (a) inserted in the stainless steel carter on the pilot - (b) evidencing the distribution system at outlet of the spiral membrane. 


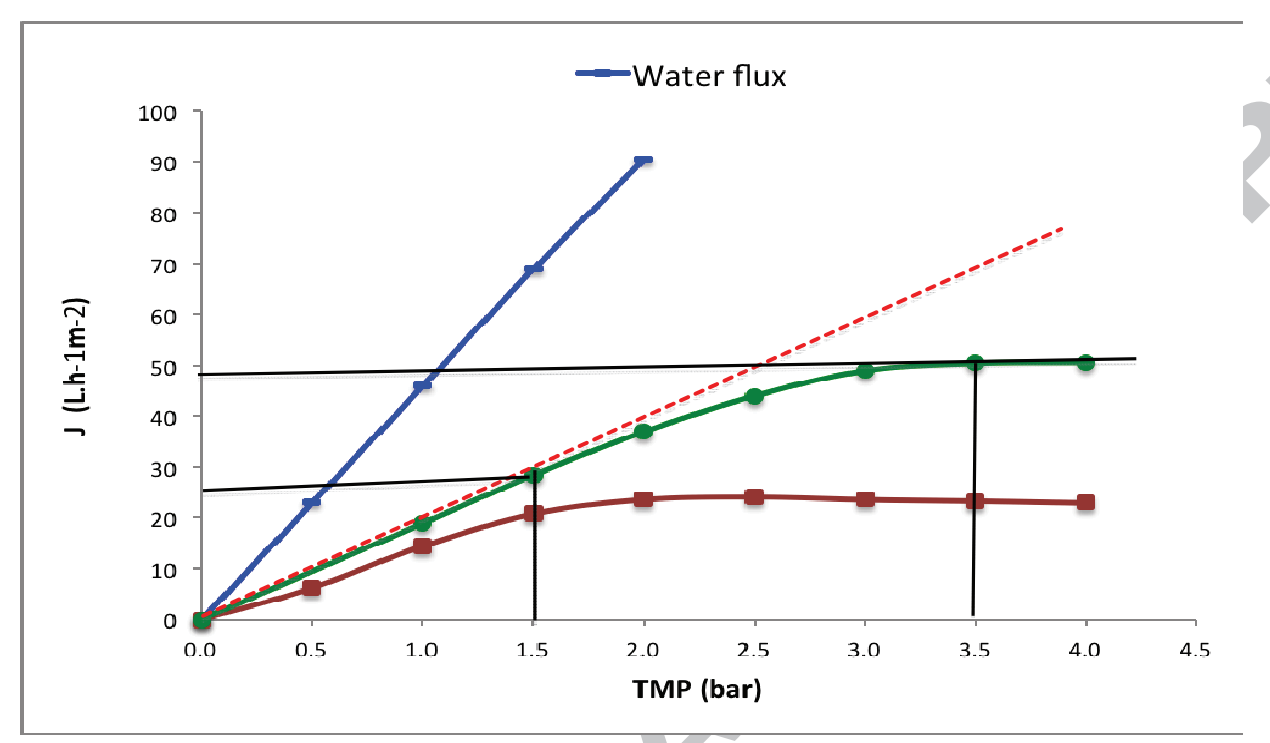

Figure 4 - Typical UF of skim milk at $46^{\circ} \mathrm{C}$, VRR $=1,0.34 \mathrm{~m} \cdot \mathrm{s}^{-1}$ with step by step increase of TMP for a flat membrane inserted in the plate and frame module with $(\bullet)$ or without retentate spacers of $1 \mathrm{~mm}$ inserted in the liquid channel. 


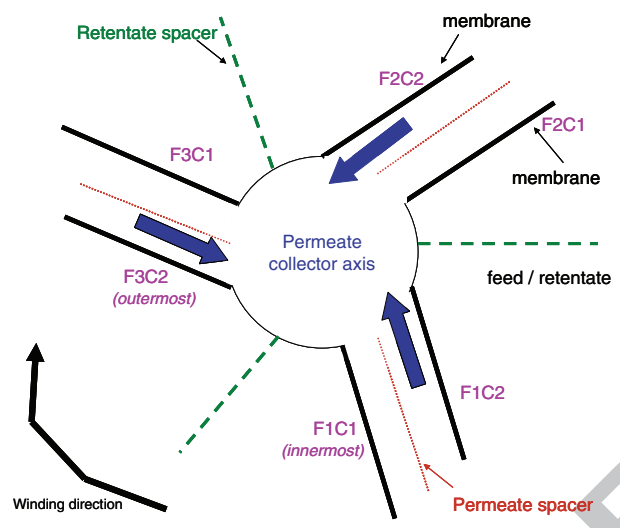

(a)

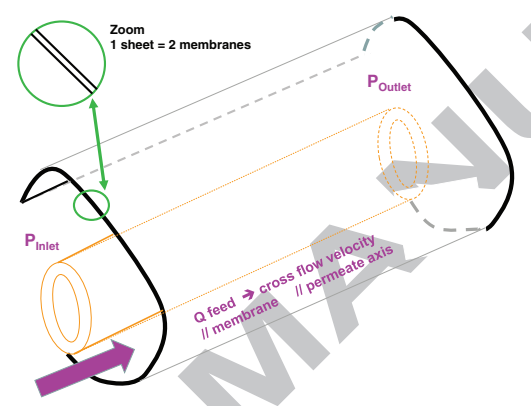

(b)

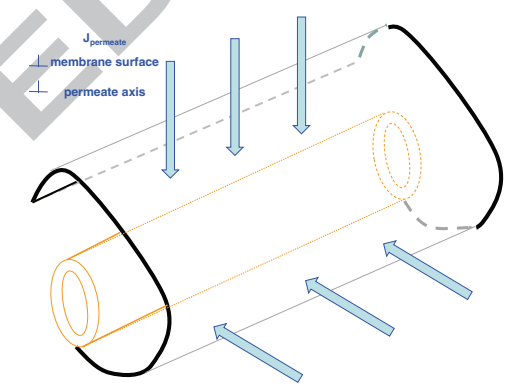

(c)

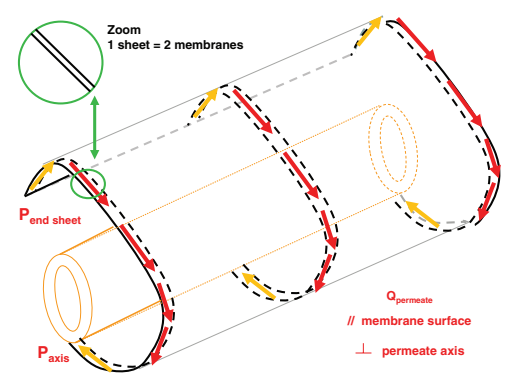

(d) 
Figure 5. Schemes of a spiral membrane (a) with 3 double sheets highlighting the different channels in which are inserted retentate or permeate spacer, respectively. Each membrane is labelled according to the same nomenclature as those used for the quantification of protein amount for the autopsied membrane. F1C1 is the innermost membrane whereas F3C2 is the outermost one - (b) single sheet made of two membranes glued back to back and direction of feed flow- (c) single sheet of membrane and direction of permeate when crossing the membrane - (d) single sheet of membrane and direction of permeate moving toward the permeate axis in the permeate channel shared by two membranes glued by to back. 


\section{ACCEPTED MANUSCRIPT}

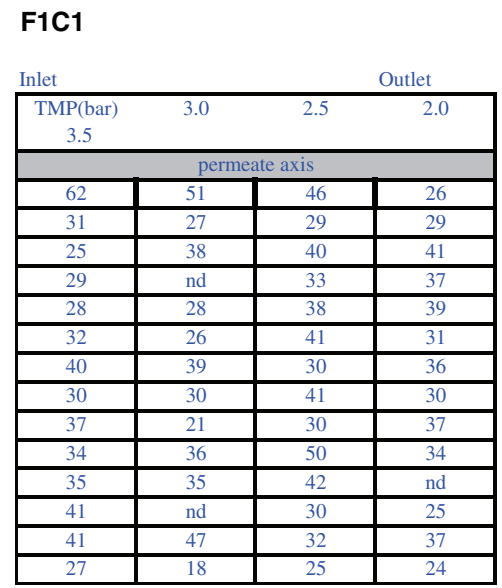

F2C1

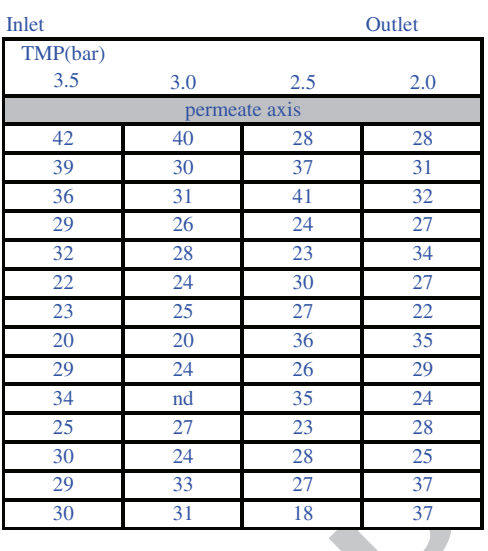

F3C1

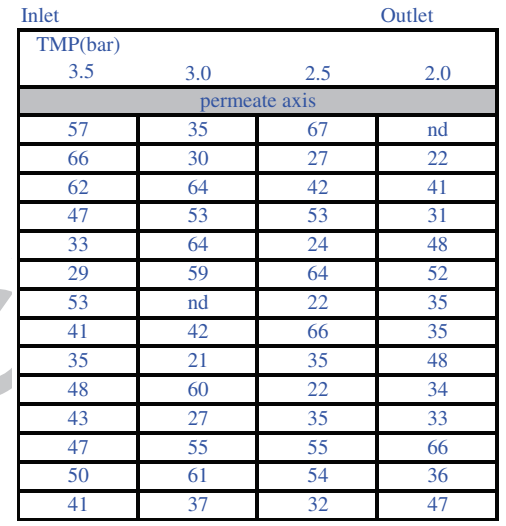

F1C2

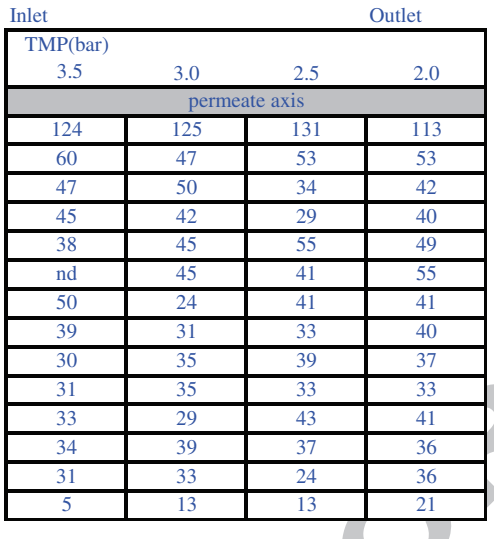

F2C2

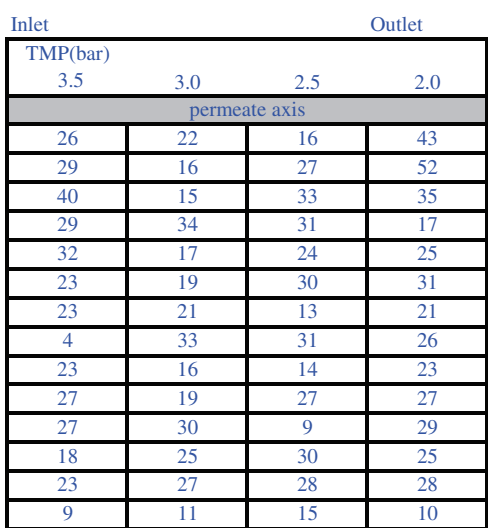

F3C2

Inlet
\begin{tabular}{|c|c|c|c|}
\hline $\begin{array}{c}\text { TMP(bar) } \\
3.5\end{array}$ & 3.0 & Outlet \\
\hline \multicolumn{4}{|c|}{ permeate axis } \\
\hline 57 & 64 & 53 & 37 \\
\hline 68 & 66 & 39 & 43 \\
\hline 50 & 49 & 29 & nd \\
\hline 51 & 46 & 29 & 26 \\
\hline 30 & 42 & 41 & 40 \\
\hline 50 & 41 & 31 & 42 \\
\hline 56 & 47 & 29 & 58 \\
\hline 52 & 34 & 53 & 38 \\
\hline 28 & 22 & 49 & 23 \\
\hline 62 & 31 & 43 & 57 \\
\hline 21 & 41 & 41 & 60 \\
\hline 16 & 21 & 35 & 38 \\
\hline 17 & 17 & 16 & 31 \\
\hline 13 & 5 & 4 & 18 \\
\hline
\end{tabular}

Figure 6. Mapping of the protein irreversible deposit in the spiral membrane determined from FTIR-ATR quantification (protein amount in $\mu \mathrm{g} . \mathrm{cm}^{-2}$ ) according to the location in the spiral membrane. The local TMP is calculated from the assumption of a linear pressure drop decrease. The membrane labels are defined on Figure 5. (nd = not determined) 


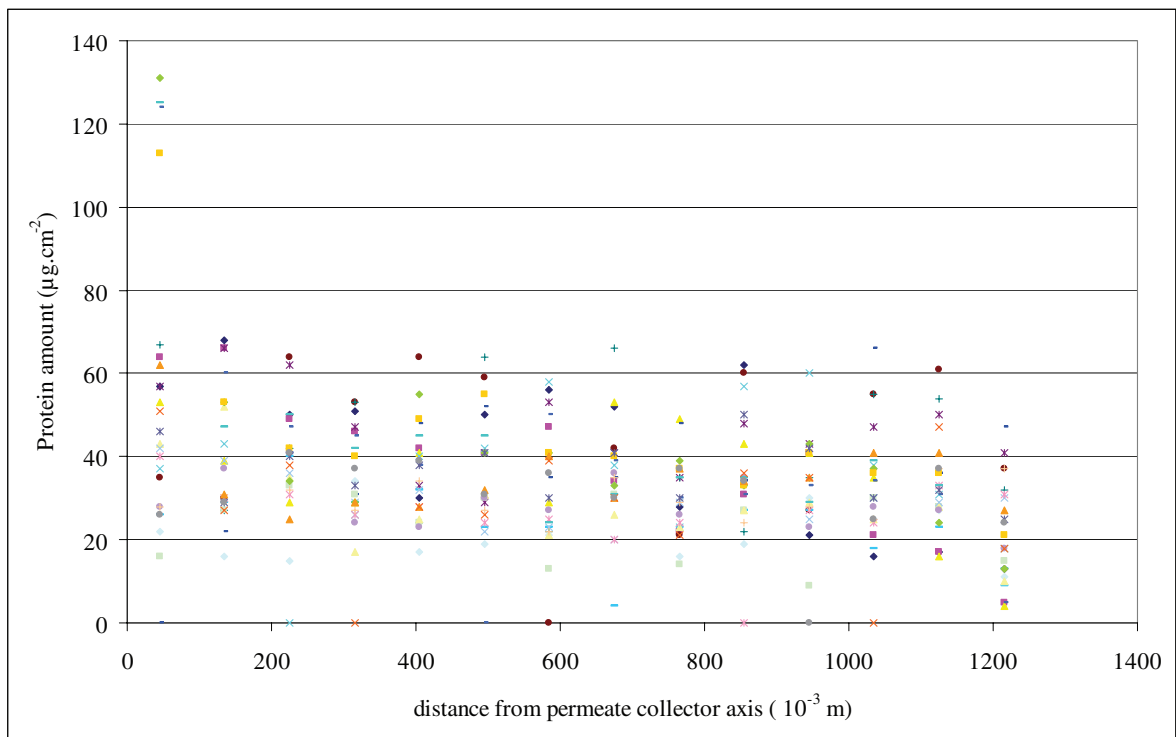

Figure 7. Irreversible amount of proteins on the spiral membrane versus the distance from the permeate collector axis (at a given distance each point correspond to a local TMP for the 6 membrane sheets). The estimation of the local average TMP is calculated from TMP at inlet and outlet and assuming a linear decrease of the pressure drop of 2.2 bar along the spiral membrane element. 


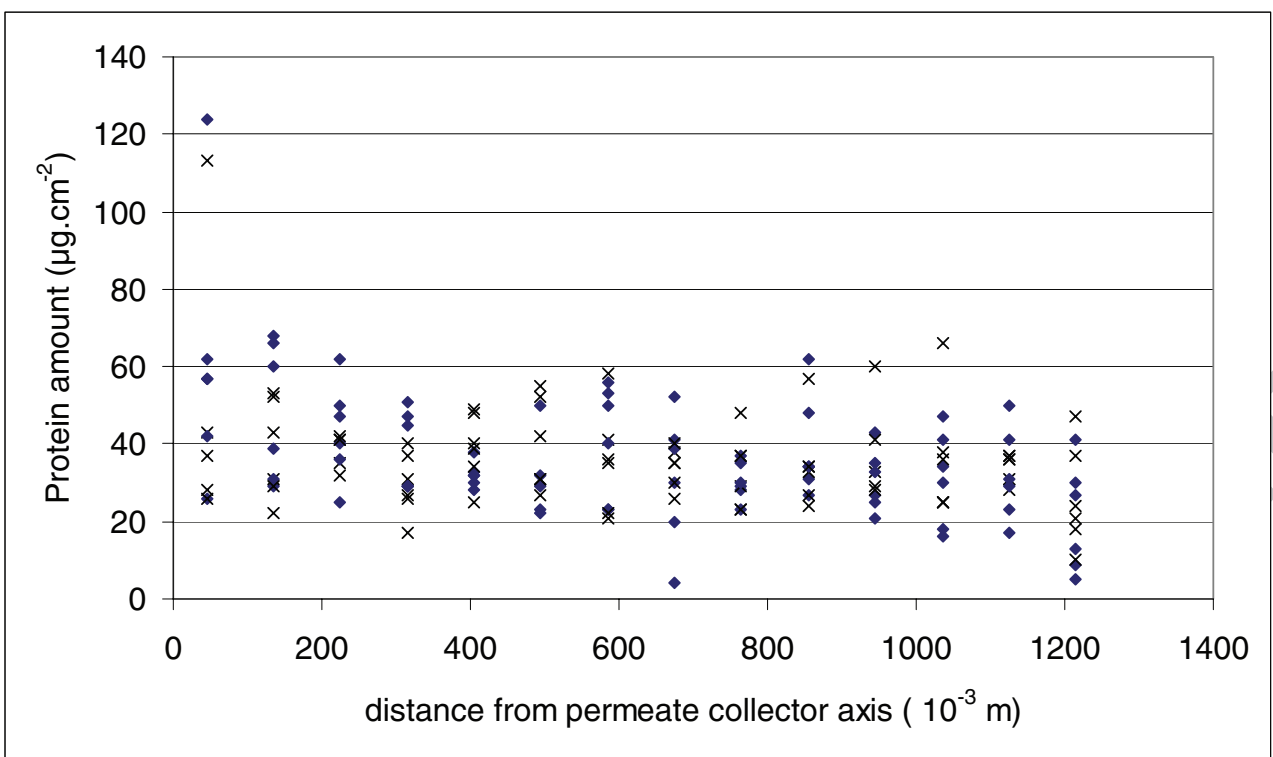

(a)

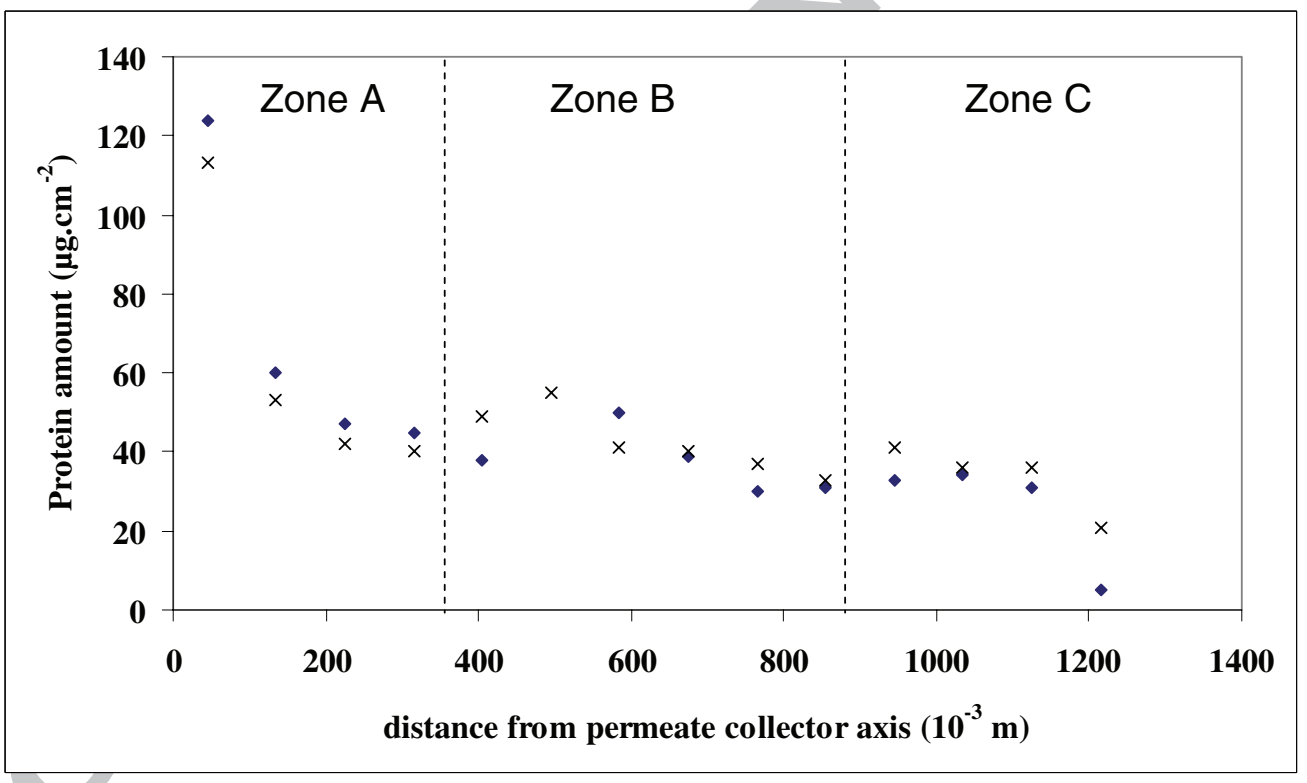

(b)

Figure 8: Amount of protein irreversible deposit on the spiral membrane versus the distance from the permeate collector axis for inlet $(\downarrow$, local TMP $=3.5$ bar $)$ and outlet $(\times$, local TMP = 2.0 bar) samples. (a) All membranes - (b) F1C2 membrane (see Figure 5 for definition).

The estimation of the local average TMP is calculated from TMP at inlet and outlet and assuming a linear decrease of the pressure drop along the spiral membrane element. 


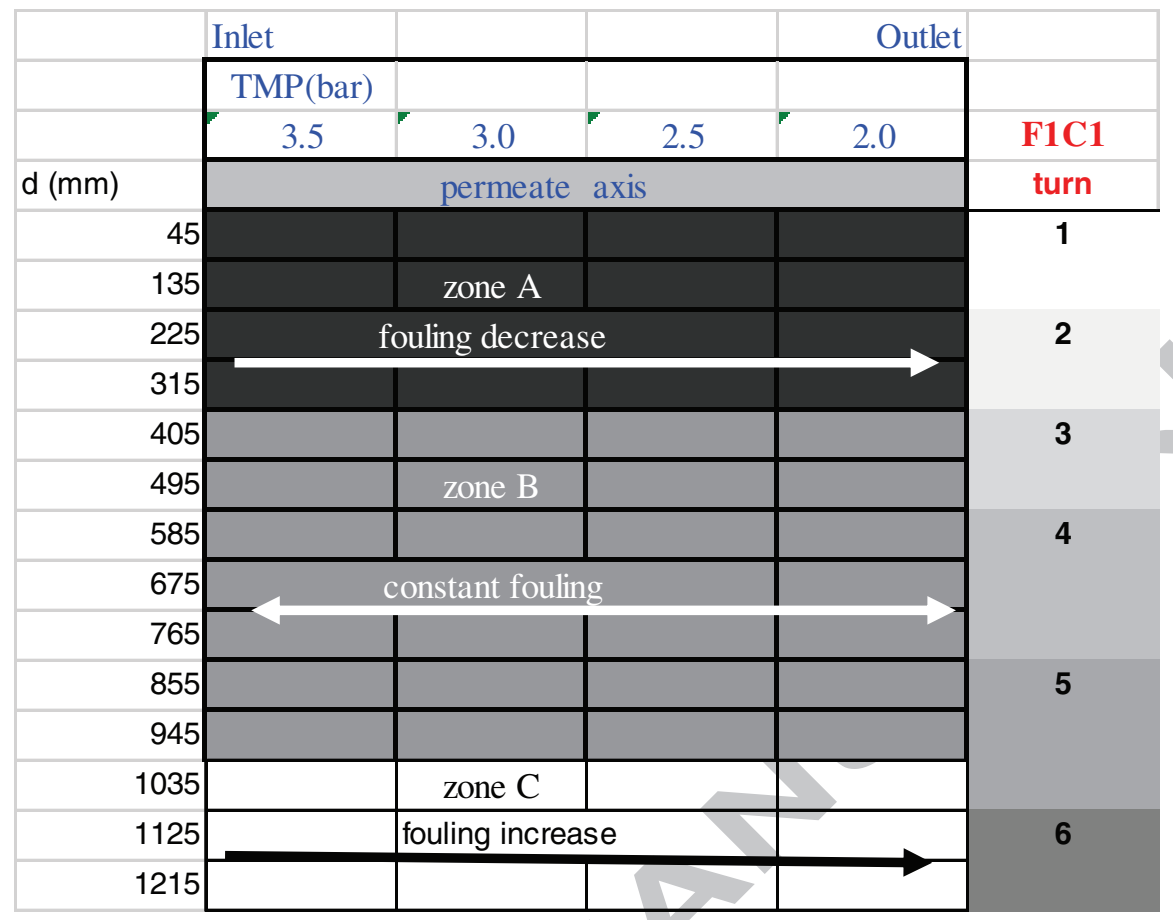

Figure 9: The 3 zones $A, B, C$ (defined Table 3) on a membrane sheet and variation of fouling from which is deduced variation of velocity/turbulences 


\section{Tables}

Table 1. Resistances of overall $\left(R_{f}\right)$ and irreversible $\left(R_{\text {irrev,initial }}\right)$ fouling due to skim milk $U F$ at $46-50{ }^{\circ} \mathrm{C}$ at several constant TMP $(*)$ for the spiral and flat membranes

\begin{tabular}{|l|l|l|l|l|l|l|l|l|}
\hline TMP (bar) & 1.5 & \multicolumn{2}{l|}{2.0} & \multicolumn{3}{l|}{3.5} & 4.0 & \\
\hline $\begin{array}{l}\text { Resitance } \\
\left(10^{12} \mathrm{~m}^{-1}\right)\end{array}$ & Spiral & Flat & Spiral & Flat & Spiral & Flat & Spiral & Flat \\
\hline $\mathrm{R}_{\mathrm{f}}$ & $40 \pm 5$ & $44 \pm 2$ & $41 \pm 1$ & $45 \pm 2$ & $47 \pm 5$ & $49 \pm 1$ & $46 \pm 3$ & $50 \pm 1$ \\
\hline $\mathrm{R}_{\text {irrev., initial }}$ & $11 \pm 2$ & $15 \pm 3$ & $13 \pm 3$ & $17 \pm 2$ & $17 \pm 3$ & $19 \pm 3$ & $16 \pm 3$ & $20 \pm 3$ \\
\hline
\end{tabular}

* TMP in spiral configuration is the average value calculated from TMP at inlet and outlet in presence of a 2.2 bar pressure drop. The pressure drop in the plate and frame module is negligible (less than 100 mbar). 
Table 2. Protein amount (from FTIR-ATR) in the initial irreversible fouling due to skim milk UF at different TMP for the flat membranes (*) and the spiral one (**).

\begin{tabular}{|l|c|c|c|c|c|c|}
\hline TMP $($ bar $)$ & 1.5 & 2.0 & 2.5 & 3.0 & 3.5 & 4.0 \\
\hline $\begin{array}{l}\text { Protein] }\left(\mu \mathrm{g} . \mathrm{cm}^{-2}\right) \\
\text { flat membrane }\end{array}$ & $13 \pm 2$ & $22 \pm 2$ & - & - & $23 \pm 2$ & $26 \pm 3$ \\
\hline $\begin{array}{l}\text { Protein] }\left(\mu \mathrm{g} . \mathrm{cm}^{-2}\right) \\
\text { spiral membrane }\end{array}$ & & $38 \pm 4$ & $35 \pm 5$ & $37 \pm 5$ & $37 \pm 5$ & \\
\hline
\end{tabular}

* TMP in flat configuration is the average value calculated from TMP at inlet and outlet, the pressure drop in the plate and frame module is negligible (less than 100 mbar). each value is the average of 9 analyses.

** TMP in the spiral configuration is the local value calculated from TMP at inlet and outlet and assuming a linear decrease of the pressure drop of 2.2 bar along the spiral membrane element. In this case the average TMP is 2.6 bar and the TMP at inlet is 3.7 bar. Each value is the average of 84 analyses. 
Table 3: Size (according to the distance toward the permeate collector axis, $d$ in $10^{-3} \mathrm{~m}$ ) of zones $A, B, C$ (defined on Figure $8 \boldsymbol{b}$ ) for each membranes. ( $n d=$ not determined)

\begin{tabular}{|l|l|l|l|}
\hline membrane & Zone A & Zone B & Zone C \\
\hline F1C1 & $0-200$ & $200-1200$ & nd \\
\hline F1C2 & $0-350$ & $400-900$ & $950-1200$ \\
\hline F2C1 & $0-250$ & $300-1050$ & $1100-1200$ \\
\hline F2C2 & $n d$ & $200-900$ & $950-1200$ \\
\hline F3C1 & $0-350$ & $400-1100$ & $1100-1200$ \\
\hline F3C2 & $0-350$ & $400-900$ & $950-1200$ \\
\hline
\end{tabular}


Highlights

- $\quad$ - mapping of irreversible fouling due to proteins is shown in a spiral membrane

- $\quad$ - fouling distribution is not related to pressure in chosen filtration conditions

- $\quad$ - fouling distribution is mainly related to variations of velocity/turbulences

- from fouling distribution the heterogeneity of fluid distribution is discussed

- variation of velocity/turbulences is proposed on a qualitative point of view 